\title{
Model test for the observation of cavity formation in sandy ground \\ - with reference to ground water level and relative density -
}

\author{
Jinyoung Kim ${ }^{\text {i) }}$, Changho Choi ${ }^{\text {ii)}}$, Jaemo Kang ${ }^{\text {iii)}}$, Wonjin Baek ${ }^{\text {iv) }}$, and Moonkyung Chung ${ }^{\text {v) }}$ \\ i) Senior Researcher, Korea Institute of Construction Technology, 2311, Daehwa-Dong, Ilsanseo-Gu, Goyang-si, Korea \\ ii) Research Fellow, Korea Institute of Construction Technology, 2311, Daehwa-Dong, Ilsanseo-Gu, Goyang-si, Korea \\ iii) Research Specialist, Korea Institute of Construction Technology, 2311, Daehwa-Dong, Ilsanseo-Gu, Goyang-si, Korea \\ iv) Associate Professor, Chonnam National University, 77Yongbong-Ro, Bukgu,Gwangju 61186, Korea \\ v) Senior Research Fellow, Korea Institute of Construction Technology, 2311, Daehwa-Dong, Ilsanseo-Gu, Goyang-si, Korea
}

\begin{abstract}
Once a cavity created in ground grows along with time with its volume extending to surface of the ground then a cave-in would occur consequently. Cases of such cave-in occurred in community area have been reported that they are typically attributable to cavities in the ground created by soil and ground water infiltrated together into the canal of sewer pipe through cracks or damaged connections of old sewer pipes. Currently, the reactive measures against the occurrence of cave-ins are usually focused on fast recovery of the part of cave-ins rather than taking actions to identify exact causes thereof or finding proper approaches therefor. Thus, the basic mechanism enabled to explain the causes or factors creating cavities in ground or the growing speed of the volume of such cavities or the relaxation in ground compaction needs to be identified. Therefore, this study was designed to simulate the damage of old sewer pipes in ground, one of major causes inducing the cave-ins. For this purpose, a model of soil tank was prepared and through which the model test employed standard sands was carried out to simulate the effects of insufficient compaction of background and changes in ground water level on the formation of cavities in a ground. The influence of the degree of ground compaction and changes in ground water level on characteristics of soil loss will be examined and, results obtained from the experiment conducted in this study will be used as basic data to perform quantitative analysis of decreasing ground density in the area causing cavities to clarify the mechanism of cavity formation.
\end{abstract}

Keywords : subsidence, model test, ground water level

\section{INTRODUCTION}

The cavities or relaxation in compaction occurred in a ground by natural or artificial cause would progress and eventually reach the surface of corresponding ground and then the cave-ins would appear consequently. Cave-ins appearing in roads are typically induced by cavities or relaxation in ground compaction which are generally resulted from soils and ground water infiltrated into underground sewer pipes through openings created by cracks or damaged joints of old sewer pipes (Bureau of Sewage Administration, Ministry of Health, Labour and Welfare, Japan, 2009). Through the regular investigation on broad area by using the GPR enabling the detection of underground cavities, such cavities especially residing the underground of roads are found to a certain extent however, the basic mechanism that could explain the causes inducing underground cavities or progression of the relaxation in ground compaction needs to be identified. Thus, this study intended to simulate the formation of ground cavity induced by changes in ground water level and by the progression of the relaxation in ground compaction around the area of the crack of old sewer pipe for which the model soil tank was prepared. By conducting the model experiment, the influence of the changes in ground water level and the progression of the relaxation in ground compaction on characteristics of underground soil migration will be examined. And then, the results obtained from the model experiment will be presented as a basic data for the quantitative evaluation of the decrease in soil density in the area of relaxed ground compaction around the cavity.

\section{MODEL TEST DEVICE AND METHOD}

\subsection{Model test device}

To simulate the ground situating at backside of damaged sewer pipe, the indoor model experiment equipment was designed and prepared by referring to the indoor experiment previously conducted in Tokyo 
University (Kuwano, 2006). As illustrated in Figure 1, the dimensions of prepared soil tank were $70 \mathrm{~cm}$ (width), $25 \mathrm{~cm}$ (length), and $50 \mathrm{~cm}$ (height). To control the level of ground water, the water tanks in dimensions of $10 \mathrm{~cm}$ (width), $25 \mathrm{~cm}$ (length), and $50 \mathrm{~cm}$ (height) made for enabling the draining of water were attached on both sides of the soil tank. And to prevent the effluent of soils between the soil and water tanks, the filter was mounted on the side of soil tank. In addition, the crack of sewer pipe was embodied with the gap of $5 \mathrm{~mm}$ in width on bottom of the soil tank through which the seepage flow comprising water and soil will be flowing by the change in level of ground water and thereby, this will also be resulted in the formation of cavity or relaxation in compaction of model ground.
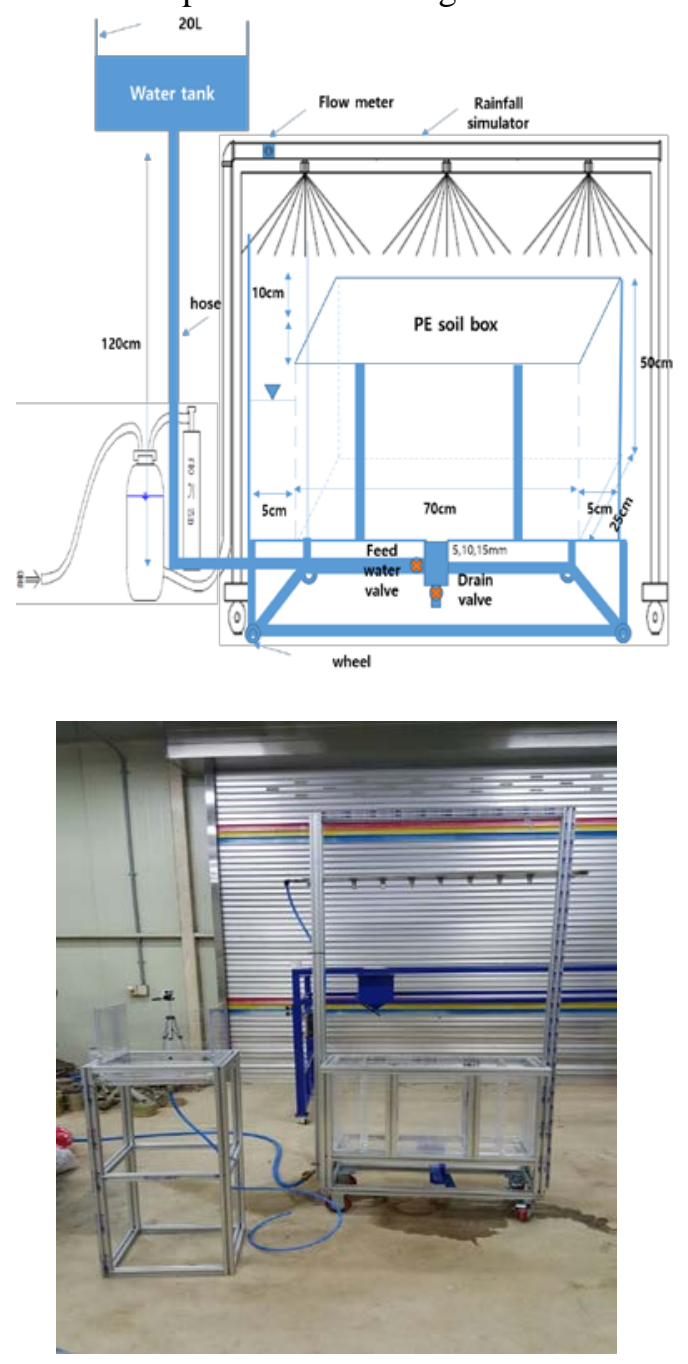

Fig. 1. Equipment of indoor model experiment.

\subsection{Method of indoor model experiment}

The preparation of model ground that was completed in the volume of $70 \mathrm{~cm} \times 25 \mathrm{~cm} \times 45 \mathrm{~cm}$ was made in a total of 9 layers $(5 \mathrm{~cm} /$ layer $)$ of wet compacted $(\mathrm{w}=5 \%)$ standard sands of Jumunjin finished at predetermined relative density. To observe the shape of deformation in the model ground to be induced the drainage of soils, the compacted model ground was paved with colored sand layer of $5 \mathrm{~mm}$ in thickness.

The model experiment was designed with the conditions summarized in Table 2 to identify the influence of changes in ground water level and relative density of model ground on formation of the cavity at backside of sewer pipe in the model ground. The shape of damaged part of sewer pipe was embodied by mounting the soil discharge outlet of $15 \mathrm{~mm}$ in diameter put on the center on bottom of the soil tank. Basic properties of the standard sands of Jumunjin employed for the experiment conducted in this study are as summarized in Table 1.

Table 1. Conditions of indoor experiment.

\begin{tabular}{|c|c|c|c|}
\hline $\begin{array}{l}\text { Relative } \\
\text { density(\%) }\end{array}$ & $\begin{array}{l}\text { Gross input } \\
\text { [added] } \\
\text { weight }\end{array}$ & $\begin{array}{l}\text { Initial } \\
\text { moisture[water] } \\
\text { content }\end{array}$ & $\begin{array}{l}\text { Ground } \\
\text { water level }\end{array}$ \\
\hline \multirow{3}{*}{75} & \multirow{3}{*}{119.4} & \multirow{3}{*}{5} & 10 \\
\hline & & & 20 \\
\hline & & & 30 \\
\hline \multirow{3}{*}{60} & \multirow{3}{*}{116.26} & \multirow{3}{*}{5} & 10 \\
\hline & & & 20 \\
\hline & & & 30 \\
\hline
\end{tabular}

Table 2. Basic Physical Properties of the Standard Sands of Jumunjin.

\begin{tabular}{lllll}
\hline Gravity & $\begin{array}{l}\text { Maximum } \\
\text { void ratio }\end{array}$ & $\begin{array}{l}\text { Minimum } \\
\text { void ratio }\end{array}$ & $\begin{array}{l}\text { Maximum } \\
\text { dry } \\
\text { density }\end{array}$ & $\begin{array}{l}\text { Minimum } \\
\text { dry } \\
\text { density }\end{array}$ \\
\hline (emax) & (emin) & & & \\
\hline & 0.94 & 0.65 & $1.59 \mathrm{t} / \mathrm{m}^{3}$ & $1.36 \mathrm{t} / \mathrm{m}^{3}$ \\
\hline
\end{tabular}

\section{RESULTS OF INDOOR MODEL EXPERIMENT AND DISCUSSION}

To examine the results to be obtained from model experiment conducted in this study, the whole process of model experiment was recorded in video images from the start of the experiment. And through the analysis of recorded video images, the primary and secondary formation of cavity were defined respectively as the stage of beginning of the formation of cavity induced by partial soil loss and as the stage continuing to the point right before the collapse of upper ground (the cave-in) by the expansion of the 
volume of primarily formed cavity. And accordingly, the 'cave-in' was defined as the stage of complete collapse of upper ground.

\subsection{Influence of changes in ground water level on the occurrence of cave-in}

To observe the occurrence of cave-in under constant condition of ground compaction, the level of ground water was gradually increased from $10 \mathrm{~cm}$ to $30 \mathrm{~cm}$ by an incremental level of $10 \mathrm{~cm}$. At the level of $10 \mathrm{~cm}$ of ground water, the cavity was formed however the cavity did not effectuated the occurrence of cave-in despite the long duration of lapsed time. But contrastingly, the cases of the level of ground water of both $20 \mathrm{~cm}$ and $30 \mathrm{~cm}$ all resulted in the occurrence of cave-ins by the cavities formed thereby, and the higher level of ground water showed comparatively faster evolution to the occurrence of cave-in.

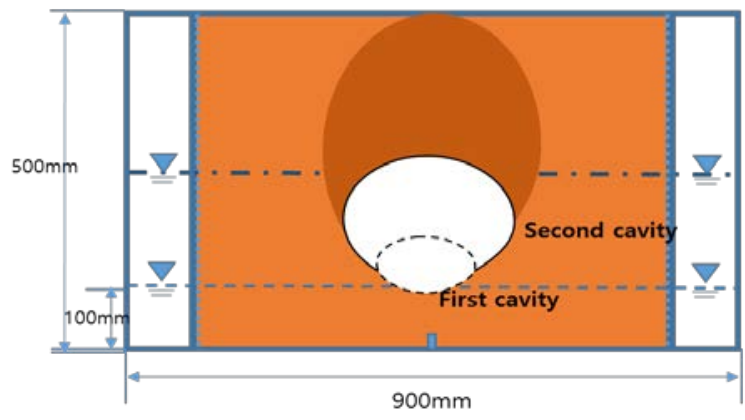

(a) Ground water level $10 \mathrm{~cm}$

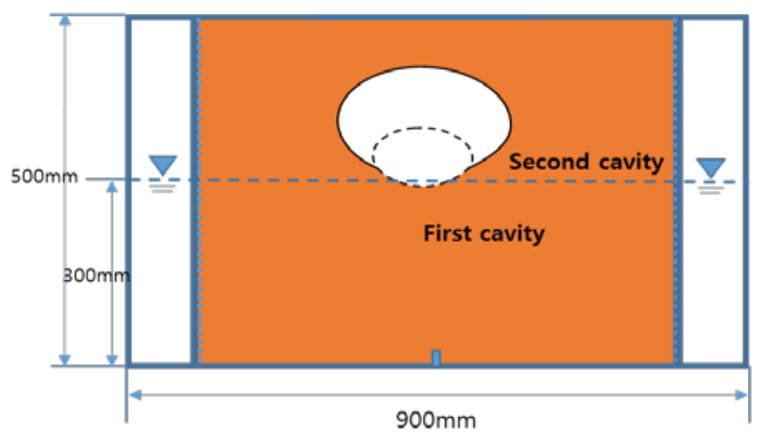

(b) Ground water level $20 \mathrm{~cm}$

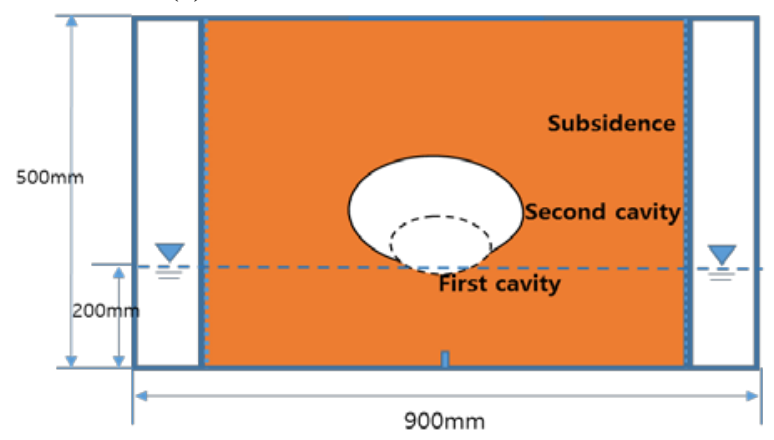

(c) Ground water level $30 \mathrm{~cm}$

Fig. 2. Illustration of the formation of underground cavities according to varied level of ground water.
In addition, the primary formation of cavity was observed from the point contacted with the surface of the level of ground water from which the formation of secondary cavity induced by subsequent relaxation in ground compaction was followed by and this was eventually succeeded by the final collapse of upper ground. Besides, the rise of the level of ground water also appeared to be directly related with the expansion of the area of the cave-in of upper ground (Fig. 2).

\subsection{Influence of the change in relative density of ground on formation of underground cavity}

To examine the influence of the change in relative density of ground under constant level of ground water, the model grounds of both $60 \%$ and $75 \%$ of relative densities were prepared for the indoor experiment conducted in this study. As summarized in Table 3, the model ground of $60 \%$ of relative density exhibited slightly faster progression toward the formation of the primary and secondary cavities and final collapse of upper ground. Thus the rise of ground water level was concluded that it was resulted in the increase of seepage force that reduced the time to formation of each cavity.

Table 3. Changes in time to formation of cavity according to varied level of ground water.

\begin{tabular}{|c|c|c|c|c|}
\hline $\begin{array}{l}\text { Relative } \\
\text { density } \\
(\%)\end{array}$ & $\begin{array}{l}\text { Groundwater } \\
\text { level } \\
(\mathrm{cm})\end{array}$ & $\begin{array}{l}\text { First } \\
\text { cavity } \\
\text { occurrence } \\
\text { (min) }\end{array}$ & $\begin{array}{l}\text { Second } \\
\text { cavity } \\
\text { occurrence } \\
\text { (min) }\end{array}$ & $\begin{array}{l}\text { subsidence } \\
\text { (min) }\end{array}$ \\
\hline \multirow{3}{*}{75} & 10 & 16.00 & 24.50 & 38.00 \\
\hline & 20 & 9.50 & 12.35 & 15.25 \\
\hline & 30 & 2.50 & 4.25 & 5.25 \\
\hline \multirow{3}{*}{60} & 10 & 14.00 & 21.00 & 36.00 \\
\hline & 20 & 4.66 & 7.25 & 9.50 \\
\hline & 30 & 2.50 & 4.16 & 5.00 \\
\hline
\end{tabular}

Figure 3 illustrates the changes in time to the formation of each cavity and to the resulting collapse of upper ground according to the data represented in Table 4 showing the comparatively faster progression to the formation of each cavity and to the final collapse of upper ground. In the case of the $60 \%$ of relative density of model ground, the final collapse of upper ground was followed right after the change in groundwater level from $20 \mathrm{~cm}$ to $30 \mathrm{~cm}$. The fast collapse of the ground can be attributable to the weaker bearing capacity of the upper ground of $60 \%$ in relative density than that of the upper ground of $75 \%$ in relative density. 


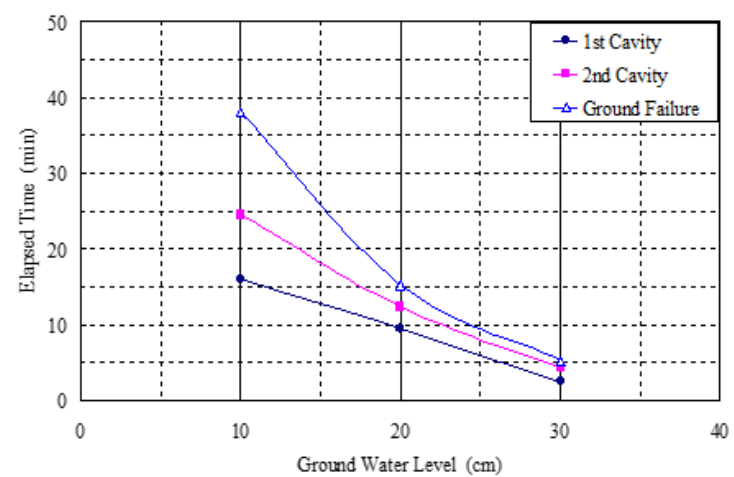

(a) $\mathrm{Dr}=75 \%$

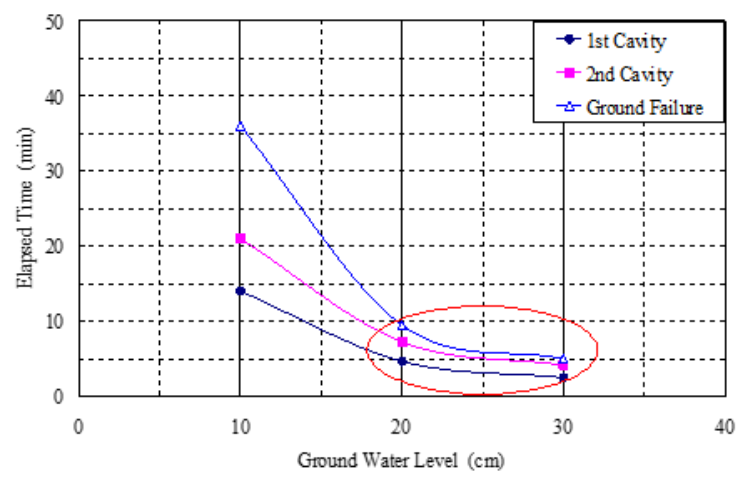

(b) $\mathrm{Dr}=60 \%$

Fig. 3. Changes in time to formation of cavity according to varied level of ground water.

\section{CONCLUSION}

In this study, the model soil tank was prepared to simulate the soil loss through a crack of damaged sewer pipe. And the indoor experiment employed the prepared model soil tank was carried out by varying the level of ground water and compaction of model ground therein to examine the influence thereof on the formation of cavities in the model ground. The results obtained from the indoor experiment are summarized as in the following:

At the $10 \mathrm{~cm}$ of groundwater level, the formation of cavity appeared in grounds of relative densities of $60 \%$ and $75 \%$ respectively however the cavities formed thereby did not eventually result in the collapse of upper ground. And along with the rise of ground water level, the comparatively fast formation of primary cavity occurred and then, by the relaxation in ground compaction followed by, the formation of secondary cavity also appeared faster and eventually resulted in the final collapse of upper ground.

The formation of cavity in model ground was observed that it was occurring along the surface of the level of ground water. And the time to formation of cavity in model ground under constant level of ground water tended to be shortened along with lower degree in ground compaction however, in the experiment employed the standard sands of Jumunjin compacted to $60 \%$ and $75 \%$ of relative density, the influence of the varied ground compaction on formation of cavity in model ground appeared insignificant and this was attributable to the insignificant difference in relative ground compaction between two cases (93\% and 95\%) corresponding each of relative ground density $(60 \%$ and $75 \%$ ). Therefore, the level of ground water level was concluded that it could be a dominant influential factor over the relative ground density on the formation of cavity in the homogeneous sandy ground.

The factors like the underground migration of soli, expansion speed of the volume of cavity, or characteristics of the area around underground cavity are expected that they could be varied by types and conditions of each ground as well as the standard sands of Jumunjin employed in this study. Thus a detailed analysis of the influence of diverse environmental factors on formation of underground cavity at each site needs respective additional experiments taking the accounts of factors of corresponding ground properties (grain-size distribution, fine fractions etc.).

\section{ACKNOWLEDGEMENT}

This work was supported by the National Research Council of Science \& Technology (NST) grant by the Korea government (MSIP) (No. CRC-14-02-ETRI).

\section{REFERENCES}

1) Kuwano, R., Horii, T., Kohashi, H. and Yamauchi, K.(2006): Defects of sewer pipes causing cave-in's in the road, Proc. 5th International Symposium on New Technologies for Urban Safety of Mega Cities in Asia, Phuket, Thailand, pp.347-353 